\title{
Pervasive plastic
}

\author{
Human manipulation of hydrocarbons - as fuel and raw materials for modern society - has changed our world \\ and the indelible imprint we will leave in the rock record. Plastics alone have permeated our lives and every corner \\ of our planet.
}

$\mathrm{N}$ o matter the location - terrestrial or ocean, rural or urban - microplastics are everywhere. Less than $5 \mathrm{~mm}$ in diameter, microplastics fall into two categories: the deliberately manufactured, primary microplastics (of which microbeads of less than $1 \mathrm{~mm}$ diameter are a subset), and secondary microplastics that are the products of larger plastics' disintegration and fragmentation. Although they are tiny, the reach of microplastics is mighty. Fewer people have descended to the deepest part of the ocean than have been to Moon and yet, in the Mariana Trench - arguably one of the most remote places on Earth - there are reports that deep-sea organisms are eating plastic ${ }^{1}$.

On land, high-discharge floods can significantly reduce microplastic contamination and maybe even eradicate microbeads from some riverbeds ${ }^{2}$. However, the consequences further downstream and in the oceans are unclear. So long as we keep feeding plastics into the system, through our continued manufacture and use, floodinduced cleansing is likely to be only a shortterm fix - if a fix at all.

In the mission to reduce the unremitting input of plastics and the damage they cause, plastic bags became a global target. As early as 2002, Bangladesh became the first country to ban lightweight plastic bags and governments around the world have followed suit by imposing some form of restriction. With increasing recognition of the major problems caused by microplastics, recent legislation has focused on microbead manufacture and sales. Regulations on their production and sale exist in the United States, Taiwan and Canada, among others, and are pending across the European Union. However, the restrictions do not even cover all deliberately manufactured microbeads, let alone the secondary microplastics formed by the breakdown of larger fragments. Although regulation is a step in the right direction, the scale of these solutions does not appear to be proportional to the scale of the problem.

Global plastic production was more than $400 \mathrm{Mt}$ in 2015, and over one third of this total was made as packaging ${ }^{3}$. The versatility

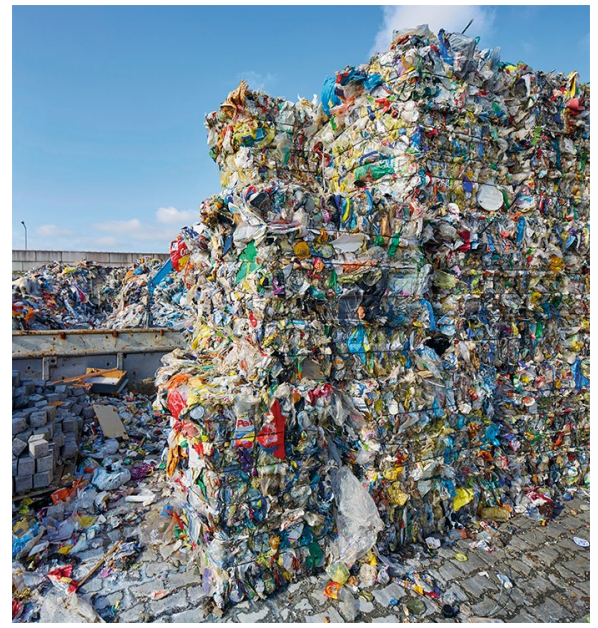

Credit: Rudi Sebastian / Alamy Stock Photo

of plastics may have made them ubiquitous in everything from food packaging to Boeing's 787 Dreamliner, but their durability has made them a persistent contaminant in our environment. For a long time, much of the world, in particular the developed world, has allowed itself an 'out of sight, out of mind' attitude to the generation of plastic waste, but this is changing.

In 2014, just over $50 \mathrm{Mt}$ of plastic was recycled - less than $20 \%$ of global production at the time ${ }^{3}$. Much of this plastic was sold to, and recycled in, China. However, the hazards associated with importing solid waste - which includes electronic waste and plastics as well as other materials - became apparent, and in July 2017 China announced that it would no longer accept yang laji (洋垃圾), or foreign garbage. The long-term effects of this rejection of other nations' refuse are not yet known. However, after years of accepting the world's unwanted plastics, China is equipped with a recycling and manufacturing industry primed to tackle its own plastic problem. In the meantime, countries such as the United Kingdom, United States and Japan are having to face up to their own piles of plastic. Without the necessary recycling capacity, the immediate response could be to turn to landfill or even incineration putting plastics alongside oil, coal and gas in the generation of electricity but also in the emission of greenhouse gases and pollutants.

Hydrocarbons, in all their forms - from fuels and plastics to the pharmaceutical industry - have defined modern life, facilitating much of our social and economic advancement. But, we are yet to fully comprehend and engage with all of the problems they leave in their wake. As we fight to keep control of ever increasing atmospheric carbon dioxide levels, it is perhaps a little reassuring that $90 \%$ of polled Europeans worry about the impact of plastic on the environment ${ }^{4}$. It is an advantage that plastic pollution is also visual pollution: it is tangible and emotive to see albatross parents unwittingly feeding plastic to their chicks (as shown on the BBC's Blue Planet). Other direct impacts of our hydrocarbon obsession - such as the insidious acidification of the oceans and the invisible killer of air pollution - may be well understood but it is harder to communicate their urgency.

Many of our actions have unforeseen consequences. The inventors of plastic, more than 50 years ago, couldn't have known the full impact their product would have - for both good and bad. As the focus of Earth Day (https://www.earthday. org/) and World Environment Day (http:// worldenvironmentday.global/) falls on ending plastic pollution, it is clear that longterm strategies, as opposed to flashfloods of good intentions, are necessary to mitigate against the unintended consequences of plastic pollution.

Published online: 30 April 2018 https://doi.org/10.1038/s41561-018-0132-6

\footnotetext{
References

1. Man-made fibres and plastic found in the deepest living organisms. NCL Press Office (14 November 2017); https:// go.nature.com/2EPErus

2. Hurley, R., Woodward, J. \& Rothwell, J. J. Nat. Geosci. https://doi. org/10.1038/s41561-018-0080-1 (2018)

3. Geyer, R., Jambeck, J. R. \& Law, K. L. Sci. Adv. 3, el700782.

4. The known unkowns of plastic pollution. The Economist (3 March 2018); https://go.nature.com/2IVtnyc
} 